\title{
PENGARUH SERVANT LEADERSHIP DAN EMPOWERMENT TERHADAP ORGANIZATIONAL CITIZENSHIP BEHAVIOUR PADA KARYAWAN ASA VILLA SEMINYAK
}

\author{
Putu Agung Pratama Sandra ${ }^{1}$ \\ I Gst Made Suwandana ${ }^{2}$ \\ ${ }^{1,2}$ Fakultas Ekonomi dan Bisnis Universitas Udayana, Bali, Indonesia \\ email: oonk.hara123@gmail.com
}

\begin{abstract}
ABSTRAK
Penelitian ini bertujuan untuk menguji pengaruh servant leadership dan empowerment terhadap organizational citizenship behavior pada karyawan Asa Villa Seminyak dengan menggunakan metode sensus (total sampling) dalam menentukan sampel sebanyak 44 responden, melalui teknik analisis regresi linear berganda. Hasil analisis membuktikan servant leadership dan empowerment secara simultan berpengaruh positif pada organizational citizenship behavior. servant leadership berpengaruh positif secara parsial pada organizational citizenship behavior. Empowerment berpengaruh positif secara parsial pada organizational citizenship behavior. Pihak manajemen Asa Villa Seminyak harus mengedepankan penerapan servant leadership demi menciptakan suasana yang aman dan nyaman di dalam bekerja. Pihak manajemen melalui pimpinan agar melaksanakan penerapan empowerment dengan kemudahan bagi karyawan dalam mencari informasi penting terkait pekerjaan sehingga mampu untuk menyelesaikan pekerjaannya.
\end{abstract}

Kata kunci : servant leadership, empowerment, organizational citizenship behavior

\begin{abstract}
The research paper aims to examine the effect of servant leadership and empowerment on organizational citizenship behavior on Asa Villa Seminyak employee, using census method (total sampling) in determining the sample of 44 respondents, Through multiple linear regression analysis technique. The result of analysis proves that servant leadership and empowerment of positive effect simultaneously on organizational citizenship behavior. Servant leadership has a positive effect partially on organizational citizenship behavior. Empowerment has a positive effect partially on organizational citizenship behavior. Asa Villa Seminyak management side must prioritize the implementation of servant leadership in order to create a safe and comfortable atmosphere in work. Management through the leadership to implement empowerment application with ease for employees in finding important information related to the job so as to be able to complete the work.
\end{abstract}

Keywords: servant leadership, empowerment, organizational citizenship behavior 
Putu Agung Pratama Sandra, Pengaruh Servant Leadership dan Empowerment...

\section{PENDAHULUAN}

Pariwisata Indonesia khususnya Bali merupakan salah satu pilar penyangga yang menjadi kekuatan ekonomi negara sehingga banyak tenaga kerja yang terserap di industri pariwisata, seiring dengan bergesernya kecenderungan modus pariwisata dari mass tourism ke individual tourism membuat tren pembangunan sarana akomodasi di Bali semakin berkembang (Mustikadewi, 2015). Kondisi seperti ini, maka perusahaan harus dapat meningkatkan keterampilan sumber daya manusianya dalam pemberian informasi, bersikap, dan dalam menjalin hubungan kepada para pelanggannya. Perusahaan yang mempunyai keterampilan yang tinggi dalam pemberian pelayanan kepada pelanggannya akan mampu menguasai atau dominan di pasar (Fitriani, 2016).

Pada berbagai aktivitas kita sehari-hari seringkali terbantu dan bahkan tergantung pada jasa. Bisnis jasa sangat berpengaruh dalam dunia modern ini (Cem and Suat, 2012). Beberapa contoh bisnis di bidang jasa antara lain adalah perbankan, hotel, villa, reparasi, serta transportasi. Terjadinya kemajuan perekonomian global, pertumbuhan pada sektor jasa semakin meningkat. Menurut laporan tahunan Bank Dunia, Global Economic Prospect and Developing Countries 1995 (Spillane, 2006: 49), sektor yang memainkan peranan semakin penting dalam revolusi globalisasi pada masa mendatang adalah sektor jasa. Sektor jasa merupakan komponen yang tumbuh paling cepat, baik dalam perdagangan maupun investasi langsung luar negeri. rovinsi Bali dikenal sebagai kota pariwisata juga mengalami pertumbuhan pada sektor jasa seperti perhotelan, villa, car rental, tour and travel. 
Tjiptono (2008: 10) menekankan bahwa jasa merupakan sesuatu yang bisa dipertukarkan namun kerapkali sulit dialami atau dirasakan secara fisik. Sejalan dengan itu, Vania dan Roy (2013) menyatakan aktivitas jasa adalah setiap tindakan atau manfaat yang dapat ditawarkan oleh satu pihak kepada pihak lain yang pada esensinya tidak berwujud dan tidak mengakibatkan kepemilikan sesuatu. Produksinya dapat atau tidak dapat dikaitkan dengan suatu produk fisik.

Berdasarkan definisi tersebut, perusahaan yang bergerak di bidang jasa harus berorientasi pada pelanggan, yaitu memuaskan para konsumen. Perusahaan memiliki tugas mendasar yaitu untuk mempengaruhi sikap dan perilaku konsumen. Tinjung dan Aida (2015) menyatakan bagi perusahaan jasa, pelayanan dihasilkan dan dikonsumsi pada waktu yang sama. Berbeda dengan perusahaan yang menjual barang, jasa pembuatan barang dihasilkan sebelum barang tersebut dikonsumsi. Oleh sebab itu, pihak perusahaan dan pelanggan terlibat secara personal dalam transaksi pelayanan (Mustikadewi, 2015). Sumber daya manusia merupakan salah satu faktor yang paling penting dalam suatu perusahaan. Oleh karena itu, sumber daya manusia harus dikelola dengan baik untuk meningkatkan efektivitas dan efisiensi organisasi, sebagai salah satu fungsi dalam perusahaan (Handoko, $2006: 212$ ).

Villa menjadi pilihan akomodasi yang banyak diminati bagi para wisatawan yang berlibur ke Bali. Akomodasi dengan tipe villa biasanya lebih disukai oleh wisatawan yang ingin berbulan madu, berlibur, bersama keluarga, maupun wisatawan yang menginginkan suasana yang lebih privat dan nyaman. Asa villa Seminyak memiliki tujuan untuk memperoleh keuntungan, selain itu 
Putu Agung Pratama Sandra, Pengaruh Servant Leadership dan Empowerment...

juga untuk melihat semakin pesatnya perkembangan dunia bisnis pariwisata di Indonesia pada umumnya dan Bali pada khususnya dengan memberikan pelayanan yang mengutamakan privasi, kenyamanan dan kemewahan dengan menawarkan villa dengan kolam renang pribadi dan taman yang luas dengan suasana yang tenang.

Perkembangan dunia bisnis pariwisata di Indonesia pada saat ini, khususnya Bali dalam menjual jasa pelayanan khususnya akomodasi pariwisata dirasakan semakin pesat. Maka dari itu bisnis jasa akomodasi pariwisata ini menjadi lahan potensial yang dirasakan oleh Asa yang harus dimenangkan dalam merebut hati wisatawan. Perkembangannya Asa mengalami penurunan penjualan pelayanan. Perkembangan penjualan jasa pelayanan akomodasi penginapan dari tahun 2011 sampai tahun 2015 dapat dilihat pada Tabel 1.

Tabel 1 menunjukkan total penjualan layanan jasa penginapan (kamar) dari tahun 2011 - 2016 cenderung berfluktuasi, ini disebabkan oleh kurangnya dukungan kerja karyawan yang tidak optimal dalam memasarkan produk dan jasa perusahaan. Terlihat bahwa peningkatan penjualan layanan jasa penginapan (kamar) tidak terlalu signifikan dan dapat dilihat penjualan pernah mengalami penurunan sangat signifikan yaitu sebesar $(1,6)$ persen pada tahun 2013 dan $(0,2)$ persen pada tahun 2015, selain adanya persaingan yang ketat, hal ini dapat disebabkan oleh kurangnya support yang dirasakan karyawan dari atasan dan tidak terlaksanakannya pemberdayaan (empowerment) sehingga karyawan tidak optimal dalam memberikan pelayanan sesuai motto perusahaan yang mengutamakan privasi, kenyamanan dan kemewahan, hal ini menyebabkan 
banyaknya pekerjaan yang tidak selesai tepat pada waktunnya. Masalah ini menunjukkan indikasi adanya masalah terhadap organizational citizenship behavior karyawan sehingga terkesan lamban dan malas dalam bekerja.

Tabel 1.

Target Penjualan Jasa Penginapan (Kamar) Asa Villa Seminyak Periode Tahun 2011-2016

\begin{tabular}{lrrr}
\hline \multicolumn{1}{c}{ Tahun } & $\begin{array}{c}\text { Target Penjualan } \\
\text { Kamar (Unit) }\end{array}$ & $\begin{array}{c}\text { Total Penjualan Kamar } \\
\text { (Unit) }\end{array}$ & Pertumbuhan (\%) \\
\hline 2011 & 7.000 & 6.450 & - \\
2012 & 8.000 & 7.310 & 13,3 \\
2013 & 8.500 & 7.190 & $(1,6)$ \\
2014 & 9.000 & 9.220 & 28,2 \\
2015 & 10.000 & 9.200 & $(0,2)$ \\
2016 & 10.500 & 9.550 & 3,8 \\
\hline Sumber: Asa Villa,2017 & & &
\end{tabular}

Thomas (2009) menyatakan perilaku individu yang dibutuhkan adalah kemampuan interpersonal yang tergolong dalam lingkup Organizational Citizenship Behaviour (OCB). Organisasi perlu didukung karyawan yang produktif dan berkomitmen tinggi untuk mencapai tujuan secara efektif (Adelia et al., 2015). Sikap tanggungjawab dan peduli pada organisasi dibutuhkan untuk membentuk loyalitas karyawan. Karyawan juga diharapkan berperan aktif dalam menyampaikan ide dalam mencapai visi dan misi organisasi. Selain itu, kepedulian pada rekan kerja dan sikap toleran dibutuhkan untuk menciptakan suasana kerja yang kondusif (Lalujan et al., 2016).

Sumber daya manusia merupakan aset paling penting dalam suatu organisasi, karena merupakan sumber yang mengendalikan organisasi serta mempertahankan dan mengembangkan organisasi dalam menghadapi berbagai tuntutan zaman (Fery, 2013). Sumber daya manusia perlu dikembangkan secara terus menerus agar diperoleh sumber daya manusia yang bermutu dalam artian sebenarnya yaitu pekerjaan yang dilaksanakan akan menghasilkan sesuatu yang 
Putu Agung Pratama Sandra, Pengaruh Servant Leadership dan Empowerment...

dikehendaki (Debora, 2016). Oleh karena itu ada deskripsi formal tentang perilaku yang harus dikerjakan (intra-role), dan yang tidak terdeskripsi secara formal yang dilakukan oleh pegawai (extra-role).

Fenomena masalah yang menyangkut perilaku organizational citizenship behavior karyawan yang rendah pada perusahaan ditunjukkan dengan sikap karyawan yang tidur pada saat jam kerja, meninggalkan tempat kerja tanpa izin, menggunakan ponsel pada saat jam kerja, dan bermain game di komputer pada saat jam kerja. Selain itu, karyawan sering berbincang-bincang tentang hal yang tidak berkaitan dengan pekerjaan pada saat jam kerja. Karyawan juga memiliki rasa kepedulian yang rendah terhadap rekan kerja yang membutuhkan bantuan. Perilaku-perilaku tersebut merupakan tindakan yang tidak mendukung efektivitas dan efisiensi dalam bekerja. Karyawan melakukan hal menyimpang atau melanggar, yang menunjukkan tanggungjawab yang rendah pada pekerjaan. Rendahnya prilaku organizational citizenship behavior karyawan dapat disebabkan oleh beberapa faktor, antara lain krisis kepercayaan terhadap pemimpin, kepuasan kerja rendah, beban kerja, rasa bosan pada pekerjaan, dan adanya masalah pribadi (Mustikadewi, 2015).

Perilaku ekstra peran atau organizational citizenship behavior para anggota organisasi ditunjukkan dengan baik, maka keefektifan peran seorang pemimpin sangatlah diperlukan (Isa, 2016). Kepemimpinan sebagai bagian integral dari efektivitas organisasi, maka kualitas dari pemimpin seringkali dianggap sebagai faktor terpenting yang menentukan keberhasilan atau kegagalan organisasi. Pemimpin yang efektif menjadikan seorang pimpinan perusahaan 
harus dapat mempengaruhi seluruh anggota organisasi yang dipimpinnya melalui cara-cara yang positif untuk mencapai tujuan organisasi (Wike dan Meily, 2012). Untuk menjadi pemimpin yang efektif, seseorang harus dapat mempengaruhi seluruh anggota yang dipimpinnya melalui cara-cara yang positif dalam berkomunikasi khususnya servant leadership style yang diterapkan (Fery, 2013).

Observasi dilakukan untuk mengetahui penyebab krisis kepercayaan terhadap pemimpin dengan pengamatan dan wawancara, penyebab krisis kepercayaan adalah diindikasikan terdapat kinerja manajer yang tidak profesional. Tindakan itu adalah kurang memperhatikan hak karyawan, dan tidak mendengarkan keluhan karyawan. Kurangnya komunikasi manajer/ pimpinan dengan karyawan mengakibatkan sulitnya menyatukan visi pimpinan dengan bawahan. Karyawan juga menyatakan bahwa citra umum pemimpin saat ini tidak dapat menjadi panutan bagi pengikutnya. Menurut karyawan, pemimpin saat ini diindikasikan bersikap tidak jujur dan inkompetensi yang menghasilkan kinerja buruk. Karyawan menilai bahwa sebagian besar pemimpin saat ini hanya mengutamakan kesejahteraan secara pribadi (Erlan, 2013).

Manajer Asa Villa Seminyak diindikasikan belum menerapkan gaya kepemimpinan servant leadership. Sikap pimpinan yang belum sepenuhnya tanggap dan memahami dengan apa yang dikomunikasikan oleh bawahan sebagai salah satu cirinya. Tidak memiliki empati kepada orang lain sekaligus bawahan. menjadi seorang pendengar yang penuh dengan empati. Kurangnya kesadaran dalam memahami persoalan yang melibatkan etika dan nilai-nilai perusahaan. Pemimpin belum berusaha meyakinkan orang lain, bukannya memaksakan 
Putu Agung Pratama Sandra, Pengaruh Servant Leadership dan Empowerment...

kepatuhan karyawannya. Manajer personalia tidak sepenuhnya memberikan apresiasi pada karyawan yang melakukan pekerjaan dengan baik. Karyawan tidak mendapatkan kesempatan untuk menyampaikan keluhan dan aspirasi. Manajer personalia sangat jarang melakukan sosialisasi apabila terdapat perubahan peraturan, maupun perubahan manajemen dalam perusahaan.

Tujuan penerapan servant leadership oleh manajer adalah untuk menciptakan suasana kerja yang menyenangkan. Kepemimpinan yang melayani diharapkan dapat menumbuhkan tanggungjawab karyawan pada pekerjaan (Lora, 2015). Perilaku-perilaku tersebut diharapkan dapat memperkecil perasaan tertekan terhadap tuntutan. Karyawan diharapkan dapat bekerja dengan produktif dan loyal pada perusahaan. Pimpinan divisi lain pada Asa Villa Seminyak belum seluruhnya memposisikan diri sebagai pemimpin yang melayani karyawan. Ditunjukkan dengan hubungan pemimpin dan karyawan yang kaku, dan kurang memperhatikan hak karyawan. Pimpinan juga tidak memberikan apresiasi pada prestasi dan tidak objektif dalam memberi penilaian terhadap pekerjaan karyawan (Michelle, 2010). Hal-hal tersebut menimbulkan krisis kepercayaan terhadap pemimpin, dan menjadi penyebab rendahnya perilaku organizational citizenship behavior karyawan Asa Villa Seminyak.

Seorang pemimpin harus dapat mewujudkan dan penerapan organizational citizenship behavior $(O C B)$ pada karyawan, yang dibantu melalui pemberdayaan sebagai wewenang untuk membuat keputusan dalam suatu area kegiatan operasi tertentu tanpa harus memperoleh pengesahan orang lain (Luthans, 2011). Empowerment atau pemberdayaan dapat diartikan sebagai perlibatan karyawan 
yang benar-benar berarti (signifikan) dalam peningkatan kinerja karyawan". Empowerment suatu cara yang amat praktis dan prodiktif untuk mendapatkan yang terbaik dari diri kita dan staf kita (Stewart, 2006:22). Pemberdayaan adalah pemberian wewenang kepada karyawan untuk merencanakan (Planning), mengendalikan (Controlling) dan membuat keputusan atas pekerjaan yang menjadi tanggung jawabnya tanpa harus mendapatkan otorisasi secara eksplisit dari atasannya (Andrea et al., 2007).

Catherine et al. (2012) menegaskan pemberdayaan merupakan alat yang dilakukan perusahaan sebagai rangsangan dalam meningkatkan motivasi serta karyawan bekerja dengan melaksanakan penerapan organizational citizenship behavior $(O C B)$. Asa Villa Seminyak juga mengalami persaingan yang ketat dengan usaha sejenis. Untuk mengantisipasi hal tersebut pihak manajemen telah mengupayakan peningkatan pelayanan terhadap pelanggan. Pelayanan yang baik dan memuaskan kepada wisatawan diperlukan adanya sikap organizational citizenship behavior pada diri karyawan.

Melalui pemaparan masalah yang telah dijabarkan, didukung dengan karya ilmiah dan teori tujuan dari karya ilmiah ini yang hendak dicapai 1) bagaimana pengaruh servant leadership terhadap organizational citizenship behavior, 2) bagaimana pengaruh empowerment terhadap organizational citizenship behavior.

\section{Citizenship Behavior}

Secara umum citizenship behavior merujuk pada 3 elemen utama yaitu kepatuhan, loyalitas, dan partisipasi. Bright and Amos (2014) mengkategorikan organizational citizenship behavior (OCB) ke dalam altruisme dan perilaku yang 
Putu Agung Pratama Sandra, Pengaruh Servant Leadership dan Empowerment...

patuh, menghormati, berinisiatif membantu orang lain tanpa pandang bulu, tidak membuang-buang waktu kerja, mampu bekerja lebih baik tanpa harus diawasi oleh pimpinan, mampu memberikan ide atau nasehat perbaikan kepada rekan kerja. Greenberg dan Baron (2011:421), ada lima dimensi dari $O C B$, yaitu: Altruism (Helping), Conscientiousness, Sportmanship (Sikap sportif), Courtesy (Kebaikan), dan Civic Virtue.

\section{Servant Leadership}

Greenleaf (1998) berpendapat bahwa servant leadership dapat mempengaruhi produktivitas dalam situasi nyata sebuah organisasi. Servant leadership yang berorientasi pada kepemimpinan yang melayani, berbasis pengetahuan, partisipatif, aspek tanggung jawab dalam proses, etika dan sosial dapat meredakan skandal atau konflik didalam organisasi.

Beberapa pakar telah mengemukakan pengertian Servant Leadership, diantaranya adalah Greenleaf (1998) dalam Mustikadewi (2015). Greenleaf (1998: 13) mendefinisikan the servant leader is a servant first. It begins with the natural feeling that one wants to serve, to serve first. Then the conscious choice bring one to aspire to lead.... the difference manifests itself in the care taken by the servantfirst to make sure that other people's highestpriority needs are being served. Pemimpin pelayan adalah seseorang yang menjadi pelayan lebih dulu. Dimulai dari perasaan alami bahwa seseorang yang ingin melayani, harus terlebih dulu melayani.

Spears (2010: 27-29) mengemukakan 10 karakteristik servant leader, karakterisitik tersebut yaitu: mendengarkan (Listening), empati (Empathy), 
penyembuhan (Healing), kesadaran (Awareness), persuasi (Persuasion), konseptualisasi (Conceptualization), kejelian (Foresight), keterbukaan (Stewardship), komitmen untuk Pertumbuhan (Commitment to the Growth of People) dan membangun Komunitas (Building Community).

Skala pengukuran Servant Leadership yaitu Servant Leadership Assement Instrument (SLAI), indikator Servant Leadership adalah sebagai berikut : kasih sayang (Love), pemberdayaan (Empowerment), visi (Vision), kerendahan hati (Humility), dan kepercayaan (Trust).

\section{Empowerment (Pemberdayaan)}

Robbins (2007:138) pemberdayaan merupakan menempatkan pekerjaan bertanggung jawab atas apa yang mereka kerjakan. Memberdayakan orang berarti mendorong mereka menjadi lebih terlibat dalam keputusan dan aktivitas yang mempengaruhi pekerjaan mereka. Andrea et al. (2007) menyatakan bahwa pemberdayaan merupakan setiap proses yang memberikan otonomi yang lebih besar kepada pekerja melalui saling menukar informasi yang relevan dan ketentuan tentang pengawasan atas faktor-faktor yang mempengaruhi prestasi kerja. Pemberdayaan karyawan merupakan pemberian wewenang kepada karyawan untuk merencanakan (Planning), mengendalikan (Controlling) dan membuat keputusan atas atas pekerjaan yang menjadi tanggung jawabnya tanpa harus mendapatkan otorisasi secara eksplisit dari manajer diatasya (Hansen and Mowen, 2007).

Pada penelitian Spreitzer (1995) dikemukan empat karakteristik umum yang dimiliki empowered people yang juga sama dengan konsep Trompenaars \& 
Putu Agung Pratama Sandra, Pengaruh Servant Leadership dan Empowerment...

Voerman (2010). Empat karakteristik umum yang dimiliki empowered people tersebut adalah 1) Sense of meaning merupakan nilai tujuan pekerjaan yang dilihat dari hubungannya pada idealisme atau standar individu, 2) Sense of competence atau self-efficacy merupakan kepercayaan individu akan kemampuan mereka dalam melakukan aktivitas mereka dengan menggunakan keahlian yang mereka miliki, 3) Sense of self-determination merupakan keahlian dalam perilaku, maka self determination merupakan suatu perasaan memiliki suatu pilihan dalam membuat pilihan dan melakukan suatu pekerjaan, 4) Sense of impact merupakan derajat dimana seseorang dapat mempengaruhi hasil pekerjaan baik strategik, administratif maupun operasional.

\section{Pengaruh servant leadership terhadap organizational citizenship behavior}

Fery et al. (2013) mengatakan bahwa peran servant leadership merupakan salah satu faktor yang dapat memberikan pengaruh positif terhadap organizational citizenship behavior. Syahfarnas (2014) memberikan pendapat yang sama peran servant leadership memberikan pengaruh positif terhadap organizational citizenship behavior. Hal ini didukung oleh Asif et al. (2013) servant leadership yang diterapkan oleh seorang pemimpin mampu meningkatkan dan memberikan pengaruh positif terhadap organizational citizenship behavior. Vania dan Roy (2013) menyatakan prilaku servant leadership memiliki pengaruh positif dalam meningkatkan organizational citizenship behavior. Fitriana (2016) menyatakan hal bahwa tingginya prilaku organizational citizenship behavior secara positif dipengaruhi oleh servant leadership. Berdasarkan pemahaman tersebut dapat dirumuskan hipotesis pertama sebagai berikut. 
$\mathrm{H}_{1}$ : servant leadership memiliki pengaruh positif terhadap organizational citizenship behavior

\section{Pengaruh empowerment terhadap organization citizenship behavior}

Andrea (2007) menyebutkan bahwa empowerment mempunyai ikatan positif dengan organization citizenship behavior. Heather et al. (2009) mengatakan empowerment sebagian dari yang mempengaruhi organization citizenship behavior karyawan. Hal ini pun dikatakan oleh Catherine et al. (2012) empowerment memiliki pengaruh yang signifikan terhadap organization citizenship behavior. Hassan (2010) membuktikan hal yang sama, dimana empowerment secara positif berpengaruh pada organization citizenship behavior. Stephanie (2015) menemukan hal yang sama dalam penelitiannya empowerment berpengaruh positif terhadap organization citizenship behavior. Berdasarkan pemahaman tersebut dapat dirumuskan hipotesis ketiga sebagai berikut.

$\mathrm{H}_{2}$ : empowerment memiliki pengaruh positif terhadap organization citizenship behavior

\section{Model Konseptual}

Berdasarkan penelusuran regresi analisis dan hasil-hasil penelitian terdahulu maka model penelitian dapat digambarkan seperti berikut.

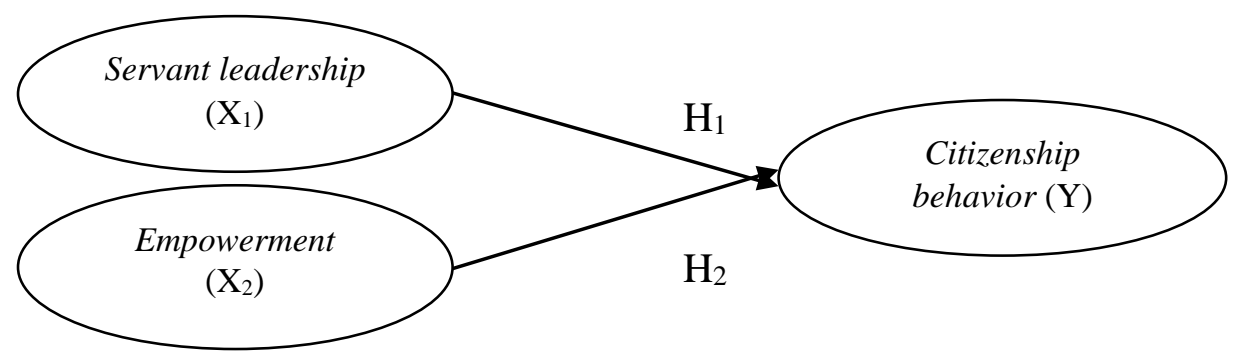

\section{Gambar 1. Kerangka Konseptual}

Sumber: Data diolah, 2017 
Putu Agung Pratama Sandra, Pengaruh Servant Leadership dan Empowerment...

\section{METODE PENELITIAN}

Penelitian ini menggunakan metode asosiatif yang bertujuan untuk mengetahui pengaruh ataupun juga hubungan antara dua variabel atau lebih (Sugiyono, 2010). Penelitian ini dilaksanakan di Asa Villa Seminyak yang berlokasi di Jalan Jl. Yudhistira, No. 32 Seminyak Bali. Dipilihnya Asa Villa Seminyak sebagai lokasi penelitian karena Asa Villa Seminyak merupakan usaha yang bergerak dibidang jasa akomodasi pariwisata khususnya villa yang mengalami persaingan yang semakin kompetitif, khususnya villa sebagai jasa penginapan dengan sistem private villa harus memberikan pelayanan yang mengutamakan privasi, kenyamanan dan kemewahan harus memiliki karyawan yang membantu dalam pengoprasiannya agar mampu memberikan layanan yang maksimal kepada wisatawan. Obyek dalam penelitian ini adalah organizational citizenship behavior. Subyek penelitian ini adalah seluruh karyawan yang bekerja di Asa Villa Seminyak. Variabel bebas adalah servant leadership ( $\left.\mathrm{X}_{1}\right)$, empowerment $\left(\mathrm{X}_{2}\right)$, dan variabel terikat adalah organizational citizenship behavior (Y).

Jenis data yang digunakan pada peenelitian ini adalah data kualitatif dan kuantitatif. Data kualitatif yang dipergunakan seperti teori-teori yang mendukung penelitian. Data kuantitatif yang dipergunakan seperti adalah data tanggapan responden terhadap kuisioner yang diberikan, jumlah populasi dan sampel responden pada karyawan Asa Villa Seminyak. Sumber data yang diginakan dalam penelitian ini adalah data primer dan data sekunder. Data primer dalam penelitian ini berupa data yang dikumpulkan dari tangan pertama, catatan, dan dipergunakan langsung dari pendapat konsumen mengenai OCB. Sedangkan data 
sekunder dalam penelitian ini berupa data panel yang merupakan data runtut waktu (time series) dan saling silang tempat (cross section) mengenai OCB di Asa Villa Seminyak.

Populasi dalam penelitian ini adalah karyawan Asa Villa Seminyak sebanyak 44 orang di luar manager, dikarenakan menggunakan variabel servant leadership sebagai variabel bebas. Sampel adalah sebagian dari jumlah dan karakteristik yang dimiliki oleh populasi. Besarnya jumlah sampel yang didapat ialah 44 orang. Sampel yang ada akan peneliti klasifikasikan berdasarkan metode sensus (Riduwan dan Sunarto, 2007:17). Metode sensus digunakan mengingat sampel pada penelitian ini masih berada pada satu perusahaan dan mudah untuk dijumpai.

Pengumpulan data dalam penelitian ini dilakukan dengan menggunakan metode observasi, pustaka dan kuisioner. Observasi adalah pengumpulan data dengan cara mengadakan pengamatan langsung ke perusahaan terhadap obyek yang diteliti, seperti aktivitas kerja karyawan. Pustaka (library research), Peneliti memperoleh data yang berkaitan dengan masalah yang sedang diteliti melalui buku, jurnal, skripsi, tesis, internet, dan perangkat lain yang berkaitan dengan judul penelitian. Kuisioner adalah cara pengumpulan data dengan menggunakan daftar pertanyaan yang disebarkan kepada responden (karyawan) berkaitan faktorfaktor yang mempengaruhi kinerja karyawan Asa Villa Seminyak.

Teknik analisis yang digunakan dalam penelitian ini adalah analisis regresi linier berganda. Analisis ini juga dapat menduga arah dari hubungan tersebut serta mengukur derajat keeratan hubungan antara satu variabel terikat dengan satu 
Putu Agung Pratama Sandra, Pengaruh Servant Leadership dan Empowerment...

variabel bebas. Dalam analisis, peneliti dibantu dengan program computer Statitical Pacage of Social Science (SPSS) versi 15.0 for Windows. Adapun bentuk umum dari persamaan regresi linier berganda menurut (Wirawan, 2002:293) sebagai berikut.

$$
\mathrm{Y}=\alpha+\beta_{1} X_{1}+\beta_{2} X_{2}+\mu i
$$

Pengujian hipotesis dengan uji ketepatan model regresi dengan menguji pengaruh variabel bebas servant leadership $\left(\mathrm{X}_{1}\right)$, empowerment $\left(\mathrm{X}_{2}\right)$, secara serempak terhadap variabel terikat organizational citizenship behavior (Y) dan uji regresi parsial (t-test) menguji signifikansi pengaruh variabel servant leadership $\left(\mathrm{X}_{1}\right)$, empowerment $\left(\mathrm{X}_{2}\right)$ secara parsial terhadap variabel terikat organizational citizenship behavior (Y).

\section{HASIL DAN PEMBAHASAN}

\section{Hasil Uji Validitas}

Sebuah instrumen dikatakan valid jika mampu mengukur apa yang seharusnya diukur, dan dapat mengungkap data dari variabel yang diteliti secara tepat. Tinggi rendahnya validitas instrumen menunjukkan sejauh mana data yang terkumpul tidak meyimpang dari gambaran tentang variabel yang dimaksud. Menurut (Santoso, 2006:135) “item yang mempunyai korelasi positif dengan kriterum (skor total) serta korelasi tinggi menunjukkan bahwa item tersebut mempunyai validitas yang tinggi pula. Syarat minimum untuk dianggap memenuhi syarat adalah kalau $r=0,3$ ”. Hasil analisisi uji validitas pada Tabel 2 menujukkan bahwa nilai korelasi dari masing-masing variabel memiliki nilai $\mathrm{r}$ 
lebih besar daripada 0,3 maka dikatakan bahwa instrumen penelitian ini adalah valid.

Tabel 2.

Hasil Uji Validitas

\begin{tabular}{clrrr}
\hline No & Variabel & Indikator & Korelasi & Keterangan \\
\hline 1 & Servant leadership $\left(\mathrm{X}_{1}\right)$ & $\mathrm{X}_{1.1}$ & 0,800 & Valid \\
& & $\mathrm{X}_{1.2}$ & 0,853 & Valid \\
& & $\mathrm{X}_{1.3}$ & 0,772 & Valid \\
& & $\mathrm{X}_{1.4}$ & 0,834 & Valid \\
\multirow{2}{*}{2} & \multirow{2}{*}{ Empowerment $\left(\mathrm{X}_{2}\right)$} & $\mathrm{X}_{1.5}$ & 0,835 & Valid \\
& & $\mathrm{X}_{2.1}$ & 0,881 & Valid \\
& & $\mathrm{X}_{2.2}$ & 0,800 & Valid \\
& \multirow{4}{*}{4} & $\mathrm{X}_{2.3}$ & 0,847 & Valid \\
& Organizational citizenship behavior & $\mathrm{X}_{2.4}$ & 0,879 & Valid \\
& (Y) & $\mathrm{Y}_{1}$ & 0,781 & Valid \\
& & $\mathrm{Y} 2$ & 0,852 & Valid \\
& & $\mathrm{Y} 3$ & 0,836 & Valid \\
& & $\mathrm{Y} 4$ & 0,775 & Valid \\
& & $\mathrm{Y} 5$ & 0,821 & Valid \\
\hline \multirow{2}{*}{ Sumber } & & &
\end{tabular}

Sumber: Data diolah, 2017

\section{Hasil Uji Reliabilitas}

Uji reabilitas bertujuan untuk mencari tahu sejauh mana kosistensi alat ukur yang digunakan, sehingga bila alat ukur tesebut digunakan kembali untuk meneliti obyek yang sama dan dengan teknik yang sama pula walaupun waktunya berbeda, maka hasil yang akan diperoleh adalah sama. Hasil uji reliabilitas dengan nilai Cronbach's Alpha untuk masing-masing variabel $>0,6$, ini berarti alat ukur tersebut akan memberikan hasil yang konsisten apabila alat ukur tesebut digunakan kembali untuk meneliti obyek yang sama disajikan pada Tabel 3 .

Tabel 3.

Hasil Uji Reliabilitas

\begin{tabular}{llrr}
\hline No & Variabel & $\begin{array}{c}\text { Cronbach's } \\
\text { Alpha }\end{array}$ & Keterangan \\
\hline 1 & Servant leadership & 0,872 & Reliabel \\
2 & Empowerment & 0,874 & Reliabel \\
\hline Sumber: Data diolah, 2017 & &
\end{tabular}


Putu Agung Pratama Sandra, Pengaruh Servant Leadership dan Empowerment...

\section{Uji Asumsi Klasik}

Uji asumsi klasik digunakan untuk memperoleh model analisis yang tepat, dimana model regresi yang tepat harus menghindari kemungkinan terjadinya penyimpangan asumsi klasik. Uji asumsi klasik yang harus dilakukan terhadap data pada penelitian ini adalah sebagai berikut.

Uji normalitas digunakan untuk mengetahui apakah nilai residual yang telah distandarisasi pada model regresi berdistribusi secara normal atau tidak. Dikatakan berdistribusi normal jika nilai residual mendekati nilai rata-ratannya (Ghozali, 2009:141). Uji normalitas dengan menggunakan uji KolmogorovSmirnov dengan signifikansi lebih besar dari 0,05 yaitu 0,161 maka dapat disimpulkan bahwa model regresi terdistribusi secara normal.

Tabel 4.

\begin{tabular}{|c|c|c|}
\hline \multicolumn{3}{|c|}{ Hasil Uji Kolmogorov-Smirnov } \\
\hline & & $\begin{array}{l}\text { Unstandardized } \\
\text { Residual }\end{array}$ \\
\hline $\mathrm{N}$ & & 44 \\
\hline \multirow[t]{2}{*}{ Normal Parameters(a,b) } & Mean & .0000000 \\
\hline & Std, Deviation & .43119695 \\
\hline \multirow[t]{3}{*}{ Most Extreme Differences } & Absolute & .169 \\
\hline & Positive & .068 \\
\hline & Negative & -.169 \\
\hline Kolmogorov-Smirnov Z & & .112 \\
\hline Asymp. Sig. (2-tailed) & & .161 \\
\hline
\end{tabular}

Uji multikolinearitas digunakan untuk melihat pembentukan korelasi yang tinggi atau sempurna diantara variabel bebas atau tidak. Jika terjadi korelasi yang tinggi dapat dikatakan terjadi murtikolinearritas. Pada model regresi yang tepat tidak boleh terjadi multikolinearitas. Multikolinearitas dapat dilihat dari nilai tolerance atau variance inflation factor (VIF). Berdasarkan Tabel 5 menujukkan 
nilai VIF (Varian Inflatation Factor) tidak lebih dari 10. Artinya, dapat disimpulkan bahwa angka tolerance tidak kurang dari 0,1, maka ini berarti bahwa tidak terjadi masalah multikoliniearitas pada model regresi yang digunakan.

Tabel 5.

Hasil Uji Multikolinearitas

\begin{tabular}{llccc}
\hline & \multirow{2}{*}{ Model } & \multicolumn{2}{c}{ Collinearity Statistic } \\
\cline { 3 - 4 } No & & Tolerance & VIF \\
\hline 1 & Servant leadership & & 0.307 & 3.255 \\
2 & Empowerment & & 0.307 & 3.255 \\
\hline \multicolumn{2}{l}{ Sumber: Data diolah, 2017 } & &
\end{tabular}

Uji heteroskedastisitas digunakan untuk mengetahui apakah model regresi yang berbentuk sudah bersifat homoskedastisitas, dimana semua varian dari residual satu pengamatan kepengamatan lain harus mempunyai nilai yang sama. Uji heteroskedastisitas dilakukan dengan menggunakan uji Glejser. Berdasarkan Tabel 6 dapat dilihat bahwa hampir semua variabel memiliki nilai sig $>0,05$ hal ini berarti bahwa model regresi yang digunakan tidak memiliki gejala heterokedasitisitas.

Tabel 6.

Hasil Uji Heteroskedastisitas (Uji Glejser)

\begin{tabular}{|c|c|c|c|c|c|c|}
\hline \multirow{2}{*}{\multicolumn{2}{|c|}{ Model }} & \multicolumn{2}{|c|}{$\begin{array}{l}\text { Unstandardized } \\
\text { Coefficients }\end{array}$} & \multirow{2}{*}{$\begin{array}{c}\text { Standardized } \\
\text { Coefficients } \\
\text { Beta }\end{array}$} & \multirow[t]{2}{*}{$\mathbf{t}$} & \multirow[t]{2}{*}{ Sig. } \\
\hline & & B & Std. Error & & & \\
\hline 1 & (Constant) & .334 & .041 & & 8.179 & .000 \\
\hline 2 & Serv. Leader & .009 & .074 & .035 & .126 & .900 \\
\hline 3 & Empower. & .036 & .074 & .135 & .487 & .629 \\
\hline
\end{tabular}

\section{Analisis Regresi Linear Berganda}

Analisis regresi linear berganda bertujuan untuk mengetahui ketergantungan suatu variabel terikat dengan satu atau lebih variabel bebas, yaitu digunakan untuk mengetahui variabel servant leadership $\left(\mathrm{X}_{1}\right)$ dan empowerment 
Putu Agung Pratama Sandra, Pengaruh Servant Leadership dan Empowerment...

$\left(\mathrm{X}_{2}\right)$ terhadap organizational citizenship behavior $(\mathrm{Y})$ dengan menggunakan SPSS.16.0. for windows Hasil analisis akan ditunjukkan pada Tabel 7.

Tabel 7.

Rangkuman Hasil Analisis Regresi Linear Berganda

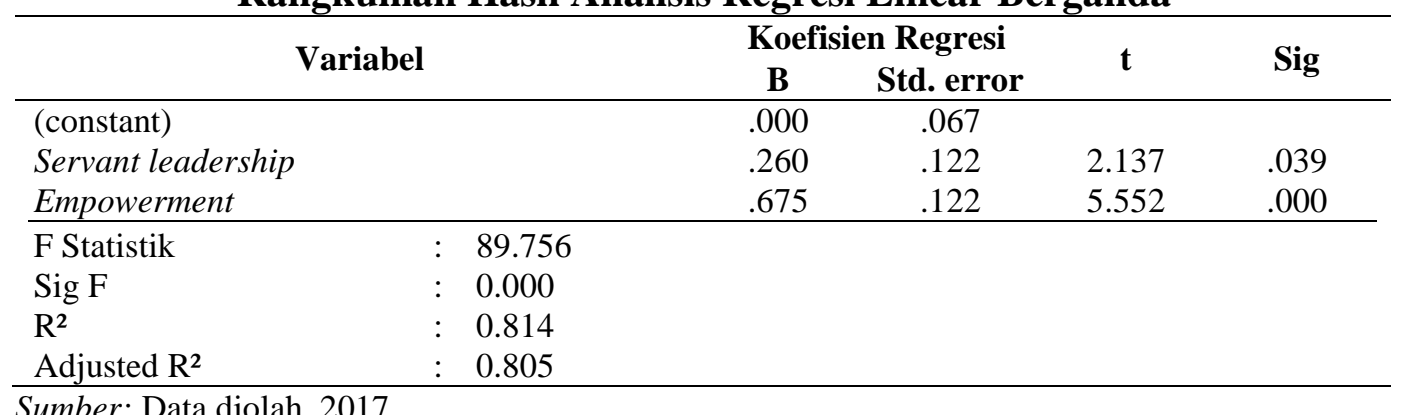

Sumber: Data diolah, 2017

Berdasarkan Tabel 7 hasil analisis menunjukkan persamaan regresi linear berganda ditulis sebagai berikut.

$\begin{array}{llll}\mathrm{Y} & =0,000+ & 0,260 \mathrm{X}_{1} & + \\ \mathrm{Se} & =(0,067) & (0,122) & 0,675 \mathrm{X}_{2} \\ \mathrm{t} & = & (2,137) & (0,122) \\ \mathrm{Sig} & = & (0,039) & (5,552) \\ \mathrm{R}^{2} & =0,814 & & (0,000) \\ \mathrm{F} & =89.756 & \text { Sig F }=0,000\end{array}$

Berdasarkan persamaan hasil regresi linear berganda tersebut dapat diuraikan bahwa nilai konstanta sebesar 0,000 menunjukan bahwa bila servant leadership $\left(\mathrm{X}_{1}\right)$, empowerment $\left(\mathrm{X}_{2}\right)$ sama dengan nol, maka nilai organizational citizenship behavior (Y) konstant sebesar 0,000 satuan. Nilai koefisien $\beta_{1}$ sebesar 0,260 berarti menunjukkan bila servant leadership $\left(\mathrm{X}_{1}\right)$ bertambah 1 satuan, maka nilai dari organizational citizenship behavior (Y) akan mengalami penurunan sebesar 0,260 satuan dengan asumsi variabel bebas lainnya konstan. Nilai koefisien $\beta_{2}$ sebesar 0,675 berarti menunjukkan bila empowerment $\left(\mathrm{X}_{2}\right)$ bertambah 1 satuan, maka nilai dari organizational citizenship behavior (Y) akan mengalami penurunan sebesar 0,675 satuan dengan asumsi variabel bebas lainnya konstan. 


\section{Hasil Uji Ketepatan Model Regresi}

Pengujian ini dilakukan untuk mengetahui tingkat signifikansi pengaruh variabel bebas secara bersama (simultan) terhadap variabel terikat. Uji F dilakukan dengan membandingkan nilai $F_{\text {hitung }}$ dengan nilai $F_{\text {tabel }}$ pada taraf signifikansi 0,05. Berdasarkan hasil analisis pada Tabel 7 menunjukkan bahwa Fhitung sebesar 89,756 lebih besar dari nilai $F_{\text {tabel }}$ sebesar 3,23 dengan probabilitas/signifikansi sebesar $0,000<0,05$ artinya secara simultan servant leadership dan empowerment berpengaruh positif dan signifikan terhadap organizational citizenship behavior (OCB). Artinya, model dapat digunakan untuk analisa lebih lanjut atau dengan kata lain model dapat digunakan untuk mempresentasikan karena hasil goodness of fitnya baik. Hasil ini didukung oleh hasil koefisien determinasi atau $\mathrm{R}^{2}=0,814$ persen variasi tingkat OCB dapat dijelaskan oleh variasi servant leadership dan empowerment sedangkan sisanya 18,6 persen dijelaskan oleh variable lainnya yang tidak termasuk pada model.

\section{Hasil Uji Signifikansi Koefisien Regresi Secara Parsial}

Tabel 8.

\section{Hasil Analisis Uji t}

\begin{tabular}{ccccc}
\hline Variabel & thitung & t tabel & Hasil Uji t & Hasil Hipotesis \\
\hline $\mathrm{X}_{1}$ & 2,137 & 1,684 & $(2,137)<(1,684)$ & $\mathrm{H}_{0}$ diterima \\
$\mathrm{X}_{2}$ & 5,552 & 1,684 & $(5,552)<(1,684)$ & $\mathrm{H}_{0}$ diterima \\
\hline
\end{tabular}

Pengaruh tiap-tiap variabel bebas dalam model ini digunakan untuk mengetahui pengaruh variabel bebas, yaitu servant leadership $\left(\mathrm{X}_{1}\right)$ dan empowerment $\left(\mathrm{X}_{2}\right)$ secara parsial terhadap organizational citizenship behavior (Y). Uji t dilakukan dengan membandingkan nilai $t_{\text {hitung }}$ dengan $t_{\text {tabel }}$ pada taraf 
Putu Agung Pratama Sandra, Pengaruh Servant Leadership dan Empowerment...

signifikansi 0,05 dengan pengujian $\alpha=0,05$; df $=41$, sehingga $t_{\text {tabel }}(0,05: 41)$ adalah sebesar 1,684 .

Berdasarkan hasil analisis pada Tabel 8 menunjukkan hasil nilai uji $\mathrm{t}_{\text {hitung }}$ untuk servant leadership yaitu 2,137. Nilai ini lebih besar dari nilai $t_{\text {tabel, }}$ yaitu 1,684 ( $\mathrm{t}_{\text {hitung }} 2,137>\mathrm{t}_{\text {tabel }}=1,684$ ) artinya servant leadership secara parsial berpengaruh positif dan signifikan terhadap organizational citizenship behaviour Asa Villa Seminyak. Berdasarkan hasil analisis data diketahui bahwa servant leadership berpengaruh positif signifikan terhadap organizational citizenship behavior. Artinya, semakin baik penerapan servant leadership, maka ada kecenderungan terwujudnya organizational citizenship behavior di Asa Villa Seminyak. Hasil penelitian ini mendukung hasil penelitian Fery et al. (2013) mengatakan bahwa peran servant leadership merupakan salah satu faktor yang dapat memberikan pengaruh positif terhadap organizational citizenship behavior. Syahfarnas (2014) memberikan pendapat yang sama peran servant leadership memberikan pengaruh positif terhadap organizational citizenship behavior. Hasil ini didukung oleh Asif et al. (2013) servant leadership yang diterapkan oleh seorang pemimpin mampu meningkatkan dan memberikan pengaruh positif terhadap organizational citizenship behavior. Veronika (2016) menyatakan prilaku servant leadership memiliki pengaruh positif dalam meningkatkan organizational citizenship behavior. Fitriana (2016) menyatakan hal bahwa tingginya prilaku organizational citizenship behavior secara positif dipengaruhi oleh servant leadership. 
Hasil analisis uji t pada Tabel 8 menunjukkaan nilai thitung untuk empowerment yaitu 5,552. Nilai ini lebih besar dari $t_{\text {tabel, }}$ yaitu 1,684 ( $t_{\text {hitung }} 5,552$ $\left.>t_{\text {tabel }}=1,684\right)$ artinya empowerment secara parsial berpengaruh positif dan signifikan terhadap organizational citizenship behaviour Asa Villa Seminyak. Hasil analisis membuktikan bahwa empowerment berpengaruh positif signifikan terhadap organizational citizenship behavior, melalui pemberdayaan atau empowerment akan terwujudnya organizational citizenship behavior di di Asa Villa Seminyak. Hasil penelitian ini searah dengan pernyataan Andrea (2007) menyebutkan bahwa empowerment mempunyai ikatan positif dengan organization citizenship behavior. Heather et al. (2009) mengatakan empowerment sebagian dari yang mempengaruhi organization citizenship behavior karyawan. Catherine et al. (2012) empowerment memiliki pengaruh yang signifikan terhadap organization citizenship behavior. Sri dan Hasan (2015) membuktikan hal yang sama, dimana empowerment secara positif berpengaruh pada organization citizenship behavior. Stephanie (2015) menemukan hal yang sama dalam penelitiannya empowerment berpengaruh positif terhadap organization citizenship behavior.

\section{SIMPULAN DAN SARAN}

Berdasarkan hasil analisis menunjukkan bahwa servant leadership berpengaruh positif dan signifikan terhadap organizational citizenship behavior di Asa Villa Seminyak, melalui penerapan kepemimpinan servant leadership akan mampu meningkatkan sikap organizational citizenship behavior karyawan di Asa 
Putu Agung Pratama Sandra, Pengaruh Servant Leadership dan Empowerment...

Villa Seminyak. Empowerment berpengaruh positif signifikan terhadap organizational citizenship behavior di Asa Villa Seminyak. Pelaksanaan empowerment secara berkelanjutan akan mampu memberikan pengaruh positif dalam meningkatkan sikap organizational citizenship behavior karyawan di Asa Villa Seminyak.

Saran yang dapat diberikan berdasarkan hasil analisis adalah bagi pihak manajemen Asa Villa Seminyak harus mengedepankan penerapan servant leadership demi menciptakan suasana yang aman dan nyaman di dalam bekerja. Pimpinan perusahaan harus memberikan contoh yang baik dalam hal pengambilan keputusan seperti kebijakan manajemen menyangkut dengan kesejahteraan karyawan yang mesti dipertimbangkan dengan saran-saran dan masukan dari bawahan seperti kebijakan manajemen, pelaksanaan jam kerja, penyusunan anggaran kerja sebagai kepercayaan dan saling memahami kebutuhan karyawan serta untuk kepentingan perusahaan kedepan.

Pelaksanaan empowerment sangat dibutuhkan oleh setiap karyawan Asa Villa Seminyak. Pihak manajemen melalui pimpinan agar memberikan kemudahan kepada karyawan dalam melaksanakan pekerjaan seperti ketersediaan laptop yang dapat dibawa kemanapun, free wifi 24 jam sebagai akses penting dalam menggunakan sumber daya yang diperlukan oleh karyawan dalam mencari informasi sehingga mampu untuk menyelesaikan pekerjaannya. Peningkatan sikap organizational citizenship behavior karyawan di Asa Villa Seminyak sangat dibutuhkan peran pimpinan dalam membina sikap karyawan untuk menjaga rasa saling tolong menolong bagi setiap karyawan seperti membantu rekan kerja yang 
sedang sakit, saling bersinergi dalam menyelesaikan pekerjaan sehingga terciptanya hubungan yang harmonis dan terwujudnya organizational citizenship behavior diperusahaan.

\section{REFERENSI}

Adelia, Maris., Wiji Utami., dan Dewi Prihatini. 2015. Pengaruh Servant Leadership dan Kepribadian terhadap Organizational Citizenship Behavior dalam Meningkatkan Kinerja Guru di Sekolah Dasar Al-Baitul Amien (Full Day School) Jember. Artikel Ilmiah Mahasiswa, pp: 1-7.

Abdu, Ja'afaru Bambale. 2014. Relationship between Servant Leadership and Organizational Citizenship Behaviors: Review of Literature and Future Research Directions. Journal of Marketing and Management, 5(1): 1-16.

Andrea, R. Dake., Jeffrey Wong., and Stephen B. Salter. 2007. Empowerment, Motivation, and Performance: Examining the impact of feedback and Incentives on Nonmanagement Employes. Journal of Behavior Research in Acounting, 19(1): 71-89.

Asif, Shahzad., Riffat Abbas Rizvi., Aamer Waheed., Aamer Waheed., Imran Khan., Sardar M. Usman., Nabila Nazir., Ghazala Amin., and Talat Mahmood Kiyani. 2013. Linking Servant Leadership with Organizational Citizenship Behavior through Trust: An Embryonic Structural Modelling Approach. European Journal of Social Sciences, 39(2): 273-284.

Baron dan Greenberg. 2011. Behavior in Organizations.10thed. NewYork:McGraw Hill.

Baron, R.M., and Kenny, D.A. 1986. The moderator-mediator variable distinction in social psychological research: Conceptual, strategic, and statistical considerations. Journal of Personality and Social Psychology, 51(6): 1173-1182.

Bright, Mahembe., and Amos S. Engelbrecht. 2014. The relationship between servant leadership, organisational citizenship behaviour and team effectiveness. SA Journal of Industrial Psychology, 40(1): 1-10.

Catherine, Cheung., Tom Baum., and Alan Wong. 2012. Relocating empowerment as a management concept for Asia. Journal of Business Research, 6(5): 36-41. 
Putu Agung Pratama Sandra, Pengaruh Servant Leadership dan Empowerment...

Cem, Gucel., and Suat Begec. 2012. The Effect of the servant leadership on Organizational Citizenship Behavior: Case Study of A University. International Journal Of Social Sciences and Humanity Study, 4(1): 107116.

Erlan, Bakiev. 2013. The Influence of Interpersonal Trust and Organizational Commitment on Perceived Organizational Performance. Journal of Applied Economics and Business Researce, 3(3): 166-180.

Eugen, Avram., and Iustin Priescu. 2012. Access to information and empowerment perspectives in health services. Journal Procedia - Social and Behavioral Sciences, 33(3): 949 - 953.

Fery, Handi Putra. 2013. Analisis Pengaruh Komunikasi Interpersonal, Lingkungan kerja fisik dan disiplin kerja terhadap kinerja pegawai perpustakaan IAIN Iman Bonjol Padang. Tesis. Manajemen Universitas Bung Hatta.

Ghozali, Imam. 2009. Aplikasi Analisis Multivariate Dengan Program SPSS. Edisi Kedua. Semarang : Bagian Penerbit Universitas Diponogoro.

Greenleaf, R. K. 1998. Servant leadership: A journey into the nature of legitimate power and greatness. New York: Paulist Press.

Handoko, T. Hani. 2006. Manajemen Personalia dan Sumber Daya Manusia Edisi 2. Yogyakarta : BPFE UGM.

Hansen dan Mowen. 2004. Manajemen Biaya, Edisi Bahasa Indonesia. Buku Kedua. Jakarta: Salemba Empat.

Haider, Raza Abid., Amir Gulzar., and Waqar Hussain. 2015. The impact of servant leadership on organizational citizenship behaviors with the mediating role of trust and moderating role of group cohesivenessA Study of public Sector of Pakistan. International Journal of Academic Research in Business and Social Sciences, 5(3): 234-242.

Hassan, Zarei Matin., Golamreza Jandaghi., Fateme Haj Karimi., and Ali Hamidizadeh. 2010. Relationship between Interpersonal Communication Skills and Organizational Commitment (Case Study: Jahad Keshavarzi and University of Qom, Iran). European Journal of Social Sciences, 13(3): 387-398.

Lalujan, Paramita., Victor P.K. Lengkong., dan Greis M. Sendow. 2016. Pengaruh Komunikasi Organisasi dan Stress Kerja Terhadap Kepuasan Kerja Serta Dampaknya Terhadap Kinerja Karyawan di Perusahaan Umum Bulog Divisi Regional Sulawesi Utara. Jurnal Emba, 4(1): 131-142. 
Mustikadewi Kartikarini, 2015. Pengaruh Servant Leadership dan kepuasan kerja terhadap Organizational Citizenship Behaviour (OCB) Karyawan Hotel Bintang-2 di Yogyakarta. Skripsi. Manajemen Universitas Negeri Yogyakarta. pp:1-144.

Mulyadi. 2007. Sistem Perencanaan dan Pengendalian Manajemen. Indonesia: Penerbit Salemba Empat.

Robbins, S. P. 2007. Teori organisasi, struktur, desain, dan aplikasi. (Alih Bahasa: Tim Indeks). New Jersey: Prentice Hall.

Sugiyono. 2010. Metode Penelitian Kuantitatif Kualitatif dan R\&D. Bandung: Alfabeta.

Spreitzer, G. M. 1995. Psychological Empowerment In Workplace: Dimensions, Measurement and Validation. Academy of Management Journal, 38(5): 1442-1465.

Syahfarnas, Adi Putrantoro, 2014. Pengaruh kepemimpinan, komitmen organisasi dan komunikasi interpersonal terhadap Organizational Citizenship Behavior (OCB) Anggota Rotaract Club Semarang. Skripsi. Ekonomika dan Bisnis Universitas Diponegoro.

Spillane, J. 2006. Pariwisata Indonesia (Siasat Ekonomi dan Rekayasa Kebudayaan). Yogyakarta : Kanisius.

Tiur, Asi Siburian. 2013. The Effect of Interpersonal Communication, Organizational Culture, Job Satisfaction, and Achievement Motivation to Organizational Commitment of State High School Teacher in the District Humbang Hasundutan, North Sumatera, Indonesia. International Journal of Humanities and Social Science, 3(12): 247-264.

Umar, Husein. 2007. Riset Sumber Daya Manusia Dalam Organisasi. Edisi Revisi. Jakarta: PT. Gramedia Pustaka Utama.

Vania, Claresta Prabowo dan Roy Setiawan. 2013. Pengaruh servant leadership dan komitmen organisasional karyawan terhadap organizational citizenship behavior pada Blue Bird Group Surabaya. Jurnal Agora, 1(3): $1-12$. 